\title{
Revisión y limitaciones de la Investigación Militante en el estudio de los movimientos sociales
}

\section{Review and limitations of Militant Research in the social movements studies}

\author{
Javier Ortega Fernández \\ Universidad de Alicante, España. \\ j.ortega@ua.es
}

\begin{abstract}
Resumen: Los movimientos sociales de base asamblearia promueven, en muchas ocasiones, la defensa y aplicación de procesos participativos. Esta correlación también se ha incorporado al estudio de los movimientos sociales, concretamente al campo de la investigación comprometida con las transformaciones sociales. Términos epistemológicos como «conocimiento situado» (Haraway, 1995) han motivado a que desde la Investigación Militante se cuestione el mantra de la objetividad científica y, de este modo, se articulen metodologías junto y con los movimientos sociales. El presente artículo pretende seguir dicho paradigma, enmarcándose en un trabajo etnográfico sobre el movimiento antidesahucios (España). Nos haremos valer de reflexiones aplicadas en relación a la polémica triangulación militancia-academia-investigación. Entre otras cuestiones nos preguntamos: ¿es suficiente una etnografía implicada con la acción colectiva para generar un espacio de sinergia entre el conocimiento académico y los movimientos sociales?, ¿a qué limitaciones nos enfrentamos? En esta línea se realiza un ejercicio retrospectivo y (auto)crítico a partir de diferentes experiencias que tuvieron lugar durante el desarrollo del trabajo de campo. En consecuencia, se concluye que no es suficiente con la predisposición y la voluntad de generar un proyecto de investigación militante, tenemos la responsabilidad de revelar los sesgos academicistas que debilitan la articulación de prácticas epistemológicas implicadas con la acción colectiva.
\end{abstract}

Palabras clave: Investigación Militante, movimiento social, epistemología, etnografía.

Abstract: The social movements assembly usually promote the defence and application of participatory processes. This correlation has also been incorporated 
to the study of social movements, specifically to the field of research that is committed to social transformations. Epistemological terms like «Situated Knowledges» (Haraway, 1991) have motivated the Militant Research to discuss scientific objectivity. And thanks to this, they have articulated methodologies together and with the social movements. This article pretends to follow such an above mentioned paradigm within an ethnographic work on the evictions movement in Spain. We will use theoretical reflections applied all in relation to the controversial triangulation: militancy-academy-investigation. Among other questions we ask ourselves: Do we have enough with an ethnography involved with the collective action to generate a space of synergy among the academic knowledge and the social movements?, which limitations are we facing? Following this, a retrospective and critical exercise is made from different experiences which took place during the development of the work of field. In consequence, we conclude by saying that it is not enough with the predisposition and the will to generate a project of Militant Research, we should also have the responsibility to reveal those academic bias that weaken the articulation of epistemological practices involved with the collective action.

Keywords: Militant Research, social movement, epistemology, ethnography. 


\section{INTRODUCCIÓN: APROXIMACIÓN A LA INVESTIGACIÓN MILITANTE}

Es pertinente comenzar reflexionando a partir de la idea de que toda interpretación del mundo va asociada a algún tipo de práctica, por tanto, lo fundamental es conocer la orientación de la misma y saber si va encaminada a reproducir el status quo o a producir realidades alternativas (Malo, 2004). La pregunta central es: «¿de qué parte nos colocamos? (...) ¿con quién pensamos?» (íd., 2004: 35). Cuestionarse los supuestos de neutralidad empírica es todo un acto de valentía epistemológica, aunque no cabe duda de que sirve para reforzar y evolucionar en el campo de las investigaciones científicas. Así lo sugirió Donna Haraway (1995) al reflexionar sobre el término «conocimiento situado»: «lo que se conoce y cómo se conoce está en relación con la situación y perspectiva del sujeto conocedor» (íd., 1995). Pero, ¿qué relación tiene esto con la Investigación Militante?

La pregunta esencial para comprender el significante epistémico de la Investigación Militante (IM) es: ¿para qué? y ¿para quién? desarrollamos un proyecto de investigación. Si ponemos el foco en el estudio de la acción colectiva con una finalidad puramente académica, aproximarse a un movimiento social desde la IM puede ser contraproducente, en cambio, si lo hacemos como sujetos-militantes y comprometidos con los proyectos emancipadores, seguramente estaremos facilitando una experiencia que trasciende los parámetros concluyentes del cientificismo.

También es necesario tratar de dilucidar quiénes son los destinatarios finales, cuestión siempre polémica y ambigua cuando se trata de una empresa de estas características. Arturo Escobar (2008) recomienda desarrollar trabajos pensando junto y con los movimientos sociales y relegar los intereses académicos o disciplinarios a un segundo plano; ¿será esto posible? Los postulados de la Investigación-acción Participativa (IAP) vienen apuntando desde hace varias décadas en esta dirección, además dotaron al proceso investigativo de un paradigma metodológico sin precedentes (Caballero, Martín y Villasante, 2019: 27). En definitiva, la IAP sitúa al sujeto conocedor en una posición de simetría con el sujeto de estudio, siendo este último quien determina la evolución del proceso de investigación (Colectivo Ioé, 2003).

Uno de los objetivos es producir conocimiento de forma colaborativa, y no unidireccional, facilitando situaciones de (auto)reflexión grupal y participativa. No obstante, sería un error pensar que estaríamos creando algo nuevo, ya que, según sugiere Juris (2007), ya existía antes de que se iniciara el proceso de investigación. Marta Malo (2004) aporta una sugestiva reflexión en relación a diferentes problematizaciones epistemológicas a la hora de enfrentarnos la compleja tarea de realizar IM, como por ejemplo: 
(...) cómo poner a funcionar este conocimiento para la transformación social, cómo hacer operativos los saberes que ya circulan por las propias redes, cómo potenciarlos y articularlos con la práctica... en definitiva, cómo sustraer nuestras capacidades mentales, nuestro intelecto, de las dinámicas de trabajo, de producción de beneficio y/o gobernabilidad, y aliarlas con la acción colectiva (subversiva, transformadora), encaminándolas al encuentro con el acontecimiento creativo (Malo, 2004: 15).

Cabe introducir otro elemento diferenciador de la IAP para ahondar en la IM: es pertinente investigar desde los márgenes, pero ¿qué significa esto? Según Torres (2008), este método permite transgredir las lógicas dominantes de la ciencia, aunque ello no significa desarrollar investigación al margen [fuera] del sistema académico. Por tanto, hemos de instalarnos «entre el adentro y el afuera, lo instituido y lo instituyente, lo conocido y lo inédito, lo determinado y lo indeterminado» (Torres, 2008: 54). Otros autores hablan de ello en términos similares aludiendo a «la epistemología fronteriza» (Mignolo, 2003), «las situaciones límite» (Freire, 2012), «el pensamiento de umbral» (Zemelman y León, 1997) o «el nomadismo intelectual» (Maffesoli, 2004). En definitiva, un conocimiento del umbral «se esfuerza en construir nuevas categorías, incorporando no sólo lo racional-cognitivo, sino lo afectivo, lo volitivo e imaginativo» (Zemelman, 2005: 13-14).

Las prácticas investigativas que actúan desde los márgenes lo que hacen es interpretar las aportaciones teóricas como una «caja de herramientas», por tanto, se expresan de acuerdo a los intereses del estudio y no como bloques disciplinarios constreñidos. A partir de la especificidad del problema de investigación se (de)construirán, (re)articularán o (re)significarán los modelos teóricos que se consideren más oportunos (Torres, 2008: 59). Esta es la idea que defiende Zemelman (1987), calificándola como «pensamiento categorial», y viene a expresar que los modelos teóricos no definirán ni limitarán, de acuerdo a parámetros prestablecidos, cuál será la morfología del objeto de conocimiento. También influirá, irremediablemente, en el diseño de la metodología y el trabajo de campo. Aunque haya una predisposición de partir de un método de investigación específico, la idiosincrasia del objeto de estudio — véase, por ejemplo, las personas que pertenecen a un movimiento social - determinará, en última instancia, cuál será el enfoque metodológico más óptimo; son, de algún modo, los compañeros epistémicos (Holmes y Marcus, 2008: 84) con los que debemos rediseñar el trabajo de campo.

En consecuencia, cuando se opta por planificar un proyecto desde la IM se ha de asumir el escenario de incertidumbre al que nos debemos enfrentar, ya que cuando aplicamos estos principios epistemológicos sabemos de dónde partimos, pero no hasta dónde llegaremos (Malo, 2004: 35). El trabajo de campo adquiere la misma notoriedad que los procesos participativos, por ello cabría la posibilidad de que el output — ya sea a 
través de ensayos, artículos o tesis doctorales - no logre proyectar la multiplicidad de saberes coproducidos durante el proceso.

En adelante, se realiza un ejercicio retrospectivo y (auto)crítico a partir de diferentes experiencias que tuvieron lugar durante un trabajo de investigación etnográfico acerca del movimiento antidesahucios en España, en concreto sobre la organización de la Plataforma de Afectados por la Hipoteca, de Alicante (España). Nos haremos valer de reflexiones aplicadas en relación con la polémica triangulación: militancia-academia-investigación. El objetivo de partida del presente artículo se suscita a partir de las siguientes cuestiones: ¿es suficiente una etnografía implicada con la acción colectiva para generar un espacio de sinergia entre el conocimiento académico y los movimientos sociales?, ¿a qué limitaciones nos enfrentamos? Antes se hará referencia a las teorías de la subalternidad, las cuales han servido de pilares fundamentales para la presente investigación. A través de dichas teorías no sólo se ha facilitado que se incida en las dimensiones del conflicto social: opresor vs. oprimido, también alientan a que se sea crítico con el trabajo realizado y, por tanto, se discuta a posteriori para seguir reforzando los procesos de empoderamiento colectivo de los grupos subyugados.

\section{LAS TEORÍAS DE LA SUBALTERNIDAD EN EL MARCO DE LA INVESTIGACIÓN MILITANTE}

Introducimos este capítulo aproximándonos teóricamente a un concepto vinculado a la IM: la subalternidad y/o los grupos subalternos. Si bien es cierto que las primeras conceptualizaciones subyacentes a la subalternidad se inscriben en la esfera intelectual-marxista de Antonio Gramsci (2000 [1934]), la divulgación bibliográfica que aparece con más frecuencia es, principalmente, de autores y autoras ubicadas - territorial e intelectualmente - en contextos poscoloniales ${ }^{1}$ (Guha, 2002 [1982]; Spivak, 2003; Modonesi, 2010; Escobar, 1999; Hoetmer, 2009).

Pensadores como Antonio Gramsci (2000[1934]) introdujeron en la primera mitad del siglo xx a los «grupos(clases) subalternos ${ }^{2} \gg$ en la esfera del pensamiento político,

${ }^{1}$ La generalización del término desde las «epistemologías del sur» (Santos, 2006; 2012) y su uso «normativizado» en el paradigma crítico de los movimientos sociales en América Latina corre el riesgo de validarse, a nuestro juicio, expresamente para determinados territorios, relegando la subalternidad a una dimensión inherente y exclusiva de los debates de colonialidad-decolonialidad.

${ }^{2}$ En primer término cabe resaltar que Gramsci nunca habló de «subalternidad» como sustantivo y lo introduciría como una acepción meramente calificativa [para discernir el complejo perfil de los grupos do- 
concretamente en un contexto de dominación capitalista pensado desde y para Occidente. El autor italiano propone una serie de atributos para definir a los grupos subalternos; uno de ellos es situar su historia entrelazada con la de la sociedad civil, a la par que cuestiona sistemáticamente la posible unificación de estos grupos debido a que están permanentemente expuestos a la iniciativa de los grupos dominantes; «sufren siempre la iniciativa de los grupos dominantes, aun cuando se sublevan y rebelan» (Gramsci, 1975: 178). Abre, de este modo, una interesante línea para la discusión: ¿es posible producir relatos históricos protagonizados por los grupos subalternos? Debido a la función disgregada y discontinua que le confiere a los sujetos aludidos, el autor reconoce, sin vacilación, que las clases subalternas únicamente podrán adquirir una voz uniforme cuando hayan alcanzado un «triunfo». Esta correlación lógica difícilmente será aplicable al contexto de los múltiples estudios emergentes sobre la movilización subalterna (Marc Edelman, 1999; Sian Lazar, 2008; Nash, 2004; David Graeber, 2002; 2009) en los que se están sistematizando y codificando historias locales y populares narradas desde abajo.

Otro de los referentes que no podíamos obviar para reflexionar sobre la subalternidad es Ranahit Guha (2002 [1982]), historiador de origen indio que formó parte, junto a otros compañeros, de los Subalterns Studies. A diferencia de Gramsci, el pensador indio sí que trazó un enfoque epistemológico de la subalternidad y, en esta dirección, incluyó rigurosas reflexiones. En su voluntad de problematizar los relatos historiográficos en contextos poscoloniales, una de sus principales contribuciones fue preguntarse quiénes eran los autores productores de la historiografía y a qué intereses respondían. Hacerse con el dominio de las narrativas y con los códigos válidos de interpretación ha servido, según Guha, para imponer mecanismos normativos que, en última instancia, generan estados de subordinación que son asimilados como una especie de estado natural. En consecuencia, se encargan de discernir qué prácticas deben interpretarse en el campo de la política y cuáles no, un ejercicio que se consuma en la omisión de la «política del pueblo» (Guha, 2002: 36), lo que significa la invisibilidad de los conflictos acaecidos en el seno de los grupos subalternos. La pensadora india Gayatri G. Spivak (2003 [1985]) se referirá al citado sistema de dominación como «violencia epistémica»; este guante lo recogen años más tarde los pensadores y pensadoras de la poscoloniali-

\footnotetext{
minados]; este hecho lo incluye en sus valoraciones Massimo Modonesi (2010: 30), autor que ha dedicado parte de su producción académica a reconstruir el legado de la subalternidad a raíz del pensamiento originario del intelectual marxista; más concretamente, alegará que la voluntad de Gramsci nunca fue la de formular una teoría de la subalternidad, sino que «optó por una reflexión teórica ligada a la observación histórica» (íd., 2010: 30).
} 
dad, entre ellos Boaventura de Sousa Santos (2013) en su tesis sobre la «sociología de las ausencias». El sociólogo portugués coloca en el centro del debate aquellos conocimientos que se están produciendo como no existentes desde instancias académicas hegemónico-occidentales, tratando de descubrir la imposición de constructos cognitivos que calificó como modos de producción de ausencias (Santos, 2013: 24-26).

Esta ha sido la práctica común de los grupos dominantes, por lo que las instancias académicas críticas, es decir, aquellas que por su compromiso y sensibilidad se ubican junto a los desheredados, tendrán que realizar un esfuerzo adicional para evitar la reproducción de voces y subjetividades que emanan de los intereses hegemónicos (Guha, 2002 [1982]: 20). Llegados a este punto, cabe agregar que cuando nos postulamos desde la IM con el objeto de indagar, estimar y reflexionar acerca de las experiencias colectivas protagonizadas por actores subalternos, emerge la necesidad de revelar lo que Ziebechi (2007) denomina los «ecos del subsuelo». De Sousa Santos (2006), en relación con sus reflexiones dirigidas a la desconstrucción de lo que denomina «pensamiento abismal» ${ }^{3}$, observa que es imprescindible «ver cuáles son las señales, pistas, latencias, posibilidades que existen en el presente, que son señales del futuro, que son posibilidades emergentes y que son descredibilizadas porque son embriones, porque son cosas no muy visibles» (Santos, 2006: 30). Gayatri Spivak se refiere a ello como «conocimiento subyugado» (2003: 317 ), léase aquellos conocimientos ingenuos y posicionados en la parte inferior de la jerarquía epistémica con reducidos niveles de cientificidad.

En línea con este enfoque, investigadoras como Amarela Varela (2013), en su tesis sobre el movimiento de migrantes de la España de principios del siglo XXI, reconoce que los migrantes-activistas, a través de su militancia, desarrollaban luchas objetivables por «los papeles» al mismo tiempo que combatían el estigma de la exclusión social [ciudadana] que pesaba sobre su condición de «inmigrantes» (2013: 169-177). Desde una perspectiva similar, Arturo Escobar (1999) concluye que en determinados movimientos populares conformados por personas pobres y situadas en los márgenes del sistema social sus principales prioridades eran las de constituirse como «ciudadanos». Por consiguiente, la realidad de las subjetividades subalternas encuentra en los movimientos sociales dimensiones amplias y complejas en las que florecen (re)significaciones que franquean los objetivos «oficiales» que se les asignan.

${ }^{3}$ El sociólogo portugués Boaventura de Sousa Santos hace alusión permanente en su tesis a la idea de «pensamiento abismal» para referirse a la concesión que se hace a la ciencia moderna para que dirima, en términos universales, lo que es verdadero y lo que es falso. Por tanto, es lo que permite que se genere el eterno debate en las ciencias sociales de lo que se considera «científico» respecto de lo «no científico» (2013: 33). 


\section{ETNOGRAFIANDO AL MOVIMIENTO ANTIDESAHUCIOS DESDE LA INVESTIGACIÓN MILITANTE}

En España, en aquel escenario socio-político convulso ulterior al movimiento 15M, se escenificó en los medios de comunicación y en las calles de nuestras ciudades una multiplicidad de luchas sectoriales catalogadas por muchos como movimientos sociales. En este sentido se abría un abanico de posibilidades para producir conocimiento crítico junto a sus protagonistas. ¿Por qué puse mi atención en el movimiento antidesahucios y no en otros? ¿Fueron las reivindicaciones por el derecho a la vivienda y/o el dramático problema de los desahucios los factores desencadenantes de la elección? El interés militante-académico lo focalicé en las personas que participaban en el movimiento social, en concreto los hombres y mujeres a los que (se) les atribuía la condición de «activistas» de la Plataforma de Afectados por la Hipoteca (PAH), reconociendo que estos no eran activistas «al uso», es decir, su procedencia era, a priori, de contextos de subjetividad situados en los márgenes de la esfera sociopolítica; en definitiva, habían sido sujetos reproductores de una praxis social hegemónica y acrítica. Tratando de no perderme en generalidades, y con la idea de producir un trabajo etnográfico, me decanté por una organización de la PAH perteneciente a un territorio específico: Alicante ${ }^{4}$ (España). $\mathrm{Su}$ elección se explica, por un lado, como laboratorio social en el cual descifrar un activismo-militante alejado de los grandes núcleos urbanos que hegemonizan, discursiva y orgánicamente, la red de organizaciones locales (véase, por ejemplo, Madrid o Barcelona); aunque su especificidad la asociamos sobre todo a las relaciones personales que tuve la oportunidad de tejer en etapas anteriores. En definitiva, agregué ese criterio metodológico que recogen autores como Hammersley y Atkinson (1994) cuando confirman la predisposición de muchos científicos sociales a moverse más por intereses personales que por intereses «científicos» a la hora de decantarse por un determinado lugar (Hammersley y Atkinson en Jabardo, 2014: 63).

\section{La etnografía como enfoque y no como técnica de investigación}

Tratando de ser consecuente con los principios de la IM, escogí la etnografía como instrumento preferente para explorar en profundidad el campo de estudio. Es preciso

${ }^{4}$ Alicante, una ciudad ubicada al sudeste de la península ibérica — desvinculada de otros centros de producción crítica del Estado español como Madrid o Barcelona-, fue el emplazamiento que escogimos para redefinir la investigación etnográfica. 
señalar que dicho método no lo aplicamos como mera técnica instrumental de investigación como ha podido inscribirse en el paradigma positivista de las ciencias sociales (Guiamet y Saccone, 2015). Para ser más concisos, se incluyó como eje articulador del proceso epistemológico.

En la fase iniciática — aunque resulte polémico desde algunas disciplinas científicas- no delimité, más allá de la observación participante, qué tipo de técnicas de investigación utilizaría ni qué sujetos serían los informantes clave, por lo que la casuística y la libre dinámica del trabajo etnográfico fueron precisando qué tipo de herramientas metodológicas se decidían ir incorporando a la investigación. La lectura que se ha realizado de la etnografía ha transitado entre los fenómenos globales y la realidad local, cuestión que ha estado presente durante todo el trabajo de campo. Como investigador me he enfrentado a situaciones en las que, como se dice coloquialmente, «los árboles no me permitían ver el bosque», es decir, la mirada se limitaba a las ocurrencias del día a día, por lo que los ejercicios de (auto)crítica no cesaban. Estas circunstancias afectaban consecuentemente a la exhortación que apunta Marcus y Fischer (1986) al hablar de que «la etnografía debe ser capaz de captar el contexto histórico de sus sujetos y registrar la acción constitutiva de los sistemas internacionales políticos y económicos sobre el nivel local, donde el trabajo de campo tiene lugar frecuentemente» (1986: 39).

Una de las finalidades que se perseguía con este método era la de adquirir cualidades técnicas para ubicar el perfil de los y las informantes como sujetos con capacidad de agencia (Ibáñez, 1985). Otro factor determinante deviene por la adecuación del citado método a la comprensión de la realidad social como un «todo estructural» en el cual, cualquier hecho, por insignificante que parezca, puede resultar enormemente significativo (Kosik, 1967). Este planteamiento me permitía acceder a múltiples experiencias susceptibles de análisis y no limitada la comprensión de los fenómenos a los presupuestos teóricos adquiridos.

El grosso del trabajo etnográfico ha versado sobre dos técnicas específicas: por un lado, la observación participante, y, de forma simultánea, la articulación de relatos de vida mediante entrevistas en profundidad. A través de la observación participante se ha generado un proceso flexible e inconcluso; cada gesto, diálogo o emoción vivenciada y/o registrada han sido ingredientes válidos para redactar los capítulos etnográficos pertinentes. Se ha complementado el trabajo de campo con relatos de vida. En un principio se diseñó como complemento a la observación participante, pero muy pronto fue adquiriendo una posición metodológica trascendental. Ante la necesidad de observar el presente desde el precepto de un «presente histórico» (Rockwell, 2009), planteé entrevistas 
abiertas en la que mis informantes describieran, en un clima de máxima confianza ${ }^{5}$, sus propias narrativas y experiencias de vida.

Hacer etnografía significaba emprender una senda de coinvestigación junto a individuos que venían instituyéndose desde un pasado reciente como actores protagonistas de la historia local, por lo que la misión no era otra que la de subirme al tren del movimiento social, sentarme junto a sus pasajeros y, de modo [muy] progresivo, ir estrechando lazos de confianza y compañerismo. Anónimo, activista, investigador, militante, observador, compañero..., por todos estos perfiles he transitado desde el trabajo de campo, todos ellos necesarios y cuasi imprescindibles si el deseo era trascender los métodos de investigación al uso.

\section{Las fases del trabajo de campo: anónimo, activista, investigador, militante, observador, compañero...}

El trabajo de campo se articuló a partir de una estrategia metodológica razonada, clasificándose en dos fases temporales distintas. La primera de ellas, cuasi exploratoria, abarcaría un periodo de seis meses, de enero a junio de 2015. El objetivo central de esta fase era desarrollar ampliamente la observación participante asistiendo a todos los espacios de reunión - tanto formal como informal—y reivindicación del colectivo. En esta etapa redacté un denso diario de campo en el que se describiría detalladamente todo el proceso de observación; en concreto trataba de mostrar una atención preferente a tres categorías analíticas: el discurso de los activistas sobre el significante racional y simbólico de la organización de pertenencia, las relaciones intersubjetivas que se estaban constituyendo en el plano del movimiento social y el impacto sociopolítico de la organización en la esfera local y global.

Dicha herramienta me subsumía en un estado sosegado, apacible y reflexivo para pensar detenidamente en la organización y, sobre todo, en las personas que conformaban la organización. Durante los meses previos pude consultar bibliografía teórica sobre el estudio de los movimientos sociales, al igual que «literatura activista» (ensayos, artículos de opinión, etc.) sobre la propia PAH, aunque esto no eximió de que se iniciara el trabajo de campo desde una disposición relativamente «virgen». El

${ }^{5}$ Hemos escogido esta técnica en una segunda fase de investigación metodológica tras experimentar una estancia de más de un año con los informantes. Este hecho nos ha facilitado poder acceder a sus testimonios desde actitudes de mayor confianza y amabilidad por ambas partes. 
recibimiento por parte del grupo fue cordial desde el inicio, pero he de reconocer que los lazos de reciprocidad afectiva se fueron estrechando paulatinamente. La primera fase se complementó con entrevistas informales en los lugares comunes de la organización y la recopilación de información gráfica, noticias de prensa y artículos relevantes. En definitiva, fue medio año de trabajo de campo intensivo, con más de doscientas páginas de diario de campo y, lo más importante, recibiendo gradualmente el calor y la hospitalidad de un conjunto de personas con una sensibilidad arrolladora.

La segunda fase sobresale por la consolidación de un trabajo más sistémico y metódico. Ya había determinado, en mayor o menor medida, el planteamiento de investigación y, por ende, estaba en disposición de delimitar cuáles serían los criterios metodológicos principales. Durante este periodo las relaciones intersubjetivas con las informantes se acrecentaron y, de este modo, las condiciones epistemológicas para desarrollar una etnografía en concordancia con los principios de la IM eran más que favorables. La observación participante seguía siendo una técnica ininterrumpida durante la estancia de campo, aunque es de recibo admitir que la densidad descriptiva del diario de campo fue debilitándose. En lo que afectaba a mi rol de investigador, algunos informantes, especialmente aquellos con los que generé mayores vínculos afectivos, dejaron de distinguirme como investigador y tendían a dirigirse a nuestra persona como «compañero». A decir verdad, este estado me suscitaba ciertas controversias, inclusive llegué a plantearme en continuadas ocasiones si mi sensibilidad con los objetivos del movimiento social sesgaría sustancialmente el trabajo etnográfico. No obstante, opté por hacer una relectura de la IM y lo integré como una oportunidad, advirtiendo que la nueva disposición facultaba la posibilidad de acceder a experiencias y relatos que sin un vínculo afectivo sería enormemente dificultoso.

Tras transcurrir un año de la segunda fase, y después de realizar reiteradas colaboraciones mediante asesoramiento, propuestas, consejos y/o intervenciones en espacios de reunión, diseñé una nueva técnica que conectara con el pasado de los y las protagonistas. Por consiguiente, durante los meses de mayo a julio de 2016 registré un total de doce relatos de vida dirigidos a los miembros más activos de la organización. El interés se centró en indagar y ahondar en las experiencias de vida sin un guion hermético, aunque instigando a los informantes a que me narraran desde su infancia cómo habían transcurrido los años hasta llegar a la PAH. Con el tiempo fui consciente de que esto sólo podía desarrollarse en una fase avanzada del trabajo de campo, y así se hizo; la mayoría de entrevistas se desenvolvieron en un ambiente de complicidad, sinceridad y emotividad sin precedentes. 


\section{REVISITANDO EXPERIENCIAS DESDE LA INVESTIGACIÓN MILITANTE: LUCES Y SOMBRAS}

\section{La perspectiva del sujeto conocedor}

El miedo a dejar que transcurriesen los años y no se tuviera nada —o casi nada — que aportar a los procesos de movilización que ocurrían semanalmente en nuestro entorno me empujó a (re)pensar cómo —y sobre todo para qué — desde el espacio académico era posible actuar. No fue una decisión sencilla. Cabe recordar que las personas que ponemos en una balanza la exploración con base científica y la implicación militante solemos buscar un equilibrio permanente que nos conduce a un cuestionamiento profesional-personal continuo.

La presente investigación se gesta en un contexto determinado que fluctúa entre el eco de la oleada de movilizaciones propagada a raíz del «movimiento 15M» (España), la primavera árabe (Túnez) y el Occupy Wall Street (EE. UU.) (Castells, 2014) y los espacios de creación de saberes colaborativos hibridados por la producción académica y el influjo militante. Siendo consciente de la dificultad que encarna producir discursos académicos alternativos y contrahegemónicos a través de organismos institucionales (Agulles, 2010; Cuesta, 2010), estimé oportuno poner el acento en aquellos espacios que, al margen de las presiones academicistas, configuran modelos de pensamiento que problematizan los imaginarios de dominación. La irrupción del 15M en mayo de 2011 (España) alentó a muchos jóvenes investigadores a erigirse como «actores protagonistas y responsables de la historia»; en mi caso, he de reconocer que me invadían los emergentes marcos del «no nos representan», «lo llaman democracia y no lo es», o «no es una crisis, es una estafa», Con este «nuevo lenguaje», posiblemente esclavo de nuestro tiempo, decidí emprender una ilusionante aventura académico-militante que, a través del presente artículo, trataré de problematizar.

A continuación, exploraré diferentes experiencias de campo sobre las cuales se tratará de dar respuesta al objetivo principal del presente artículo: ¿es suficiente la etnografía aplicada a los movimientos sociales para generar un espacio de sinergia entre el conocimiento académico y los movimientos sociales?, ¿a qué limitaciones nos enfrentamos?; además formularé dos interrogantes más para ampliar el análisis: ¿qué factores determinan en la práctica la posibilidad de realizar Investigación Militante?, ¿basta con la buena voluntad de la persona investigadora?

\section{Del ego intelectual a la ignorancia del investigador-militante}

Lo que expondré en adelante parte de una reflexión a posteriori. Una vez finalizado el estudio, y habiendo dejado un tiempo prudencial, me propongo hacer una revisión del 
trabajo de campo para, así, reconstruir determinados hechos que suscitan una especie de «autoflagelación epistemológica constructiva» (que me perdone el lector por semejante adjetivación).

Comenzaré advirtiendo que la revisión teórica y bibliográfica que precede al trabajo de campo fue de vital importancia, tanto en sentido positivo como negativo. Conocer, por un lado, qué es la Plataforma de Afectados por la Hipoteca (PAH) de la mano de Ada Colau y Alemay (2013a; 2013b), Carlos Macías (2013), José Taberner (2014), María Monjas (2015) o Manuel Castells (2015), entre otros, y, además, revisar a intelectuales especializados en movimientos sociales como Charles Tilly (1978; 2009), Donatella Della Porta y Mario Diani (2015), Arturo Escobar (1992; 1999) o Alberto Melucci (1994; 1996) determinó sustancialmente la forma y el modo con los que afronté la investigación. Por un lado, contaba con los recursos cognitivos básicos; inclusive es pertinente reconocer que costó sobremanera crear interrogantes nuevos que giraran en torno a este movimiento social. Sin embargo, el contacto directo con el grupo me permitió reducir los grados de «miopía militante».

Partía de un conocimiento historiográfico sobre la gestación del colectivo antidesahucios $^{6}$. Durante ese periodo las clases populares palpaban en sus propias carnes el fatal desenlace de la crisis financiera y, entre otros efectos, irrumpió el drama de los desahucios ${ }^{7}$. La PAH, lejos de establecerse como una asociación de apoyo a las víctimas de desahucio, se nutre desde sus inicios de un «espíritu activista» (Lichterman, 1996). La mayoría de fuentes consultadas subrayan el compromiso individual de cada uno de los componentes del grupo promotor de la organización. Asimismo configuraron un enfoque «activista-académico» que los vinculaba a la entidad investigadora del Observatori DESC.

${ }^{6}$ La primera PAH se creó en Barcelona en el año 2009 tras un proceso de reflexión y deliberación de un grupo de jóvenes que estaban participando de forma activa en el colectivo $V$ de Vivienda en Cataluña (organización antecesora del movimiento antidesahucios en España). A finales de ese mismo año se impulsaron también dos plataformas en territorio catalán, una fue en Terrassa (Barcelona) y la otra en Sabadell (Barcelona).

${ }^{7}$ Los desahucios eran un fenómeno que se reproducía por toda España. Según el Consejo General del Poder Judicial (CGPJ), de 2008 a 2009 casi se duplicó el número de ejecuciones hipotecarias en toda España, pasando de 58.686 a 93.319, en tan sólo un año. Barcelona era la provincia que ostentaba la primera posición en el ranking de territorios con mayor número de ejecuciones hipotecarias (10.738 en 2009), seguidas de Madrid (10.655), Alicante (7.617) y Valencia (6.553), respectivamente (Colau y Alemany, 2013a: 227-232). Estos datos no son simples números, es la constatación del nuevo escenario habitacional a la que estuvo abocada una gran parte de la sociedad civil. En la fecha en que se redacta el presente artículo todavía siguen registrando cifras elevadas de desahucios y la problemática habitacional sigue vigente. 
El citado observatorio fue una figura fundamental en la articulación del movimiento en Cataluña (Colau y Alemany, 2013a) y en la extensión del discurso contrahegemónico en favor del derecho a la vivienda (Ortega, 2015); prácticamente desde sus inicios el Observatori DESC adquiere la doble función académica-activista. Combina la incidencia política con la investigación y organización de cursos y charlas, todo ello sin perder de vista la importancia del trabajo en red y de la participación en campañas. Por tanto, el colectivo tuvo la posibilidad de apoyarse en un espacio con un fuerte legado experiencial en dicha materia. Esto se tradujo en un tipo de activismo profesionalizado (recordemos que muchos de los y las activistas también participaban de forma paralela en dicho instituto de investigación) que combinaba los repertorios performativos $-\mathrm{y}$ ampliamente innovadores - con la producción de conocimiento a través de proyectos de investigación; en definitiva, facilitaron la constitución de lo que Enrique Laraña y Rubén Díez (2012) definen como «organización reflexiva». En este sentido, ¿qué tipo de «organización reflexiva» me iba a encontrar en la experiencia de campo? ¿Serían capaces de emular lo que estaba sucediendo en Cataluña? Lo que viene a continuación es el resultado de un ejercicio (auto)reflexivo, narrado a través de la experiencia etnográfica.

Empezaré haciendo alusión a lo ocurrido en los momentos previos a una entrevista que concerté con una las informantes clave, en concreto con la activista que manifestaba mayores dotes de liderazgo «informal». Nos encontrábamos en los primeros meses del trabajo de campo, las relaciones interpersonales con los activistas eran débiles y la confianza mutua brillaba por su ausencia. No obstante, contaba con una autocomplacencia ligada a los saberes académicos capaz de aportarme la fuerza suficiente para proyectar un horizonte de investigación militante óptimo, o eso creía. Me dejé invadir por dos prejuicios que, de algún modo, estaban interrelacionados: en primer lugar, tenía la certeza de que no sería el único perfil académico con voluntad de colaborar en la organización y, además, probablemente el grupo estaría vinculado a alguna entidad, institución o departamento universitario con el cual constituían y reforzaban su «organización reflexiva». Dichos prejuicios se desmotaron rápidamente en la conversación mantenida con nuestra informante. La activista reconoció sentirse asombrada por cuestiones como «¿estáis vinculados a algún centro de investigación?», o «¿contáis con el apoyo de algún investigador o departamento de la universidad?». Ante su rotunda negación le hablé del Observatori DESC y de los diferentes proyectos que venían realizando hasta esa fecha. Tras una larga conversación donde destacamos el papel de este tipo de entidades en el marco de los movimientos sociales, reconoció finalmente que esa opción era prácticamente inviable en su organización debido a las características y al contexto de un colectivo autónomo como la PAH de una zona periférica del Estado español (Alicante): «Este tipo de cosas solo pasan en Madrid o Barcelona», concluyó. En ese instante acepté tal 
afirmación categórica. Fueron los principios de la IM los que me empujaron a sugerirle, quizá de forma prematura, la posibilidad de constituir un proyecto a corto-medio plazo que aunara movilización, participación y academia. Para que fuese eficaz debíamos ampliar la red de contactos, así como consolidar una estructura al estilo Observatori DESC. Ese mismo día lo que anoté en el diario de campo sirvió como terapia etnográfica para empezar a replantearme los sesgos, prejuicios y, sobre todo, el ego intelectual con que había iniciado la etnografía militante. En definitiva, fue de utilidad para aterrizar en las particularidades locales del movimiento social y, sobre todo, para cuestionarme si no estaba generando demasiadas expectativas en una fase de la investigación todavía prístina.

Otro hecho anecdótico, aunque profundamente significativo, sucedió una de las tardes que acudí a una acampada de protesta junto a una sucursal bancaria en solidaridad con una familia amenazada de desahucio. Al igual que ocurriera con la experiencia descrita en el anterior párrafo, acababa de iniciar el trabajo de campo. Antes de visitar la zona de acampada decidí acudir a una librería próxima para adquirir el libro que había publicado recientemente Ada Colau y Adrià Alemany (2013b), titulado Vidas hipotecadas. De la burbuja inmobiliaria al derecho a la vivienda. Con el libro en mano me reuní con el grupo de activistas que estaban presentes en el campamento de protesta. La primera alusión vino a colación de mi reciente adquisición literaria. Pregunté si ya habían tenido la posibilidad de leer el libro, pero, para mi sorpresa, la mayoría no sabía que se había publicado y mostraron total indiferencia ante él. Mientras que, por un parte, yo lo había adquirido como un recurso formativo indispensable — recordemos que por esas fechas la mayoría de investigaciones sobre la PAH estaban en marcha y las publicaciones eran limitadas - , por otro lado, a las personas de la organización no les suscitaba apenas interés. Fui testigo en primera persona de que, pese a la voluntad de ofrecer un proyecto junto y con el movimiento social, las opiniones, creencias, actitudes y subjetividades de los y las activistas sociales serían los elementos que deberían redirigir la estructura metodológica y teórica de la investigación militante.

En cualquier caso, cuando más evidente se hizo la (auto)percepción del ego intelectual y la constatación de mi ignorancia militante fue en una de las intervenciones que realicé en una de las asambleas periódicas que organizaban semanalmente. A tal espacio de encuentro habían acudido alrededor de sesenta personas, con una sala abarrotada repleta de diferentes tipos de perfiles sociológicos: madres extranjeras con sus hijos pequeños, parejas jóvenes, hombres y mujeres solteras de mediana edad, familias de etnia gitana y/o activistas de la PAH con una larga trayectoria, entre otros. Entre los propios miembros de la plataforma era común que se generasen controversias y discusiones; algunas lograban resolverse de inmediato y otras podían llegar a prolongarse 
hasta la saciedad. El día al que aludo ocurrió lo segundo, es decir, durante las dos horas de reunión todas las intervenciones polemizaban sobre la escasa implicación de las personas que acuden a la PAH en busca de ayuda y deciden no colaborar en el conjunto de actividades y acciones de protesta que organiza el colectivo. ¿Qué podía aportar yo desde mi condición de «experto» de los movimientos sociales? ¿Debía observar desde la pasividad o era conveniente aportar una visión que sirviera para ampliar la perspectiva? Finalmente me decanté por levantar la mano y pedir turno de palabra. Las dudas no cesaron desde ese instante hasta que, casi sin darme cuenta, mi hilo de voz empezó a resonar en la sala. Los autores clásicos de los movimientos sociales junto a la literatura activista de la PAH inundaron el discurso, apelé intensamente a las potencialidades de los movimientos sociales, al protagonismo de la PAH en el contexto histórico presente $\mathrm{y}$, especialmente, quise incidir en las transformaciones simbólicas que el movimiento antidesahucios estaba logrando entre las clases populares del país. A pesar de que mucha de la audiencia asentía durante el discurso, mi ego intelectual sospechaba que la intervención tendría un mayor impacto del que finalmente tuvo. Seguidamente se le otorgó el turno de palabra a la persona correspondiente y ésta aludió exclusivamente al tema que había planteado la interviniente que me precedía; nadie después hizo mención alguna a lo que expuse. Para el desarrollo posterior del trabajo de campo supuso una lección epistemológica fundamental. A partir de entonces reinicié la labor de investigación reconociendo que partía de una elevada ignorancia, lo cual tenía que reconocer para que no afectase negativamente a la investigación. Por tanto, era exclusivamente ese punto desde donde comenzaría a transitar hacia la coproducción de los saberes subalternos de la mano del movimiento antidesahucios.

\section{El saber militante más allá de los saberes académicos}

Aproximarse a cualquier movimiento social en calidad de experto puede resultar contraproducente, especialmente en aquellos contextos en los que la militancia utiliza un lenguaje y unos saberes específicos. No basta con comprender las lógicas relacionales y simbólicas del grupo, se hace preciso formarse en los asuntos que más les preocupa y sobre los que gira la mayor parte de su actividad militante. Ésta lección la fui aprendiendo en el transcurso del trabajo de campo mediante la observación participante. Tal y como vengo desarrollando en el capítulo anterior, continuaré con la descripción de tres experiencias, y, así, seguir reflexionado a través del enfoque aplicado. En lo que me detendré va en la línea de lo que nos sugirió una joven activista de la PAH a la que tuve el placer de entrevistar: 
Algo que me sorprendió es la gente que estaba ahí tirando del carro. No era gente que habían sido abogados o que hayan tenido estudios superiores, algunos eran albañiles, personas que se había dedicado a la construcción, gente con oficios totalmente diferentes al trabajo que hace la Plataforma... Y veía que se habían empapado las leyes y tenían un montón de conocimientos, eso me sorprendió mucho... (Anabel, joven activista de la PAH-Alicante con estudios universitarios, Alicante: 06/06/2016).

Cada semana se convocaban dos asambleas, una los viernes y otra los domingos. Se organizaban en lugares distintos: la primera en una sala cedida por el sindicato de la CGT y la segunda en una plaza pública de la ciudad. Aunque algunas voces cuestionaron la excesiva carga de reuniones, otras reconocían que se trataba de dos espacios de encuentro radicalmente distintos y con objetivos muy diferentes. Si bien en la primera el trato con las familias afectadas por desahucio era más directo, la del domingo tenía un carácter más informativo y reivindicativo. En este caso, la organización periódica de reuniones, junto al resto de acciones de protesta convocadas a lo largo de la semana, me permitía estrechar fuertes lazos afectivos con el grupo que componía el núcleo de la organización (eran alrededor de 12-14 personas, la mayoría mujeres). En lo que atañe a la disposición metodológica, en los primeros meses asumí un rol pasivo actuando como mero espectador, tanto en las reuniones como en las acciones de protesta. Con libreta en mano me ocupaba de escuchar y observar todo lo sucedido, prestando atención a los detalles más nimios para, así, recopilar la información necesaria y poder crear un relato etnográfico de calidad. Ya lo decía Kosik (1967): en una etnografía, cualquier hecho, por insignificante que parezca, puede resultar enormemente significativo. En las acciones de protesta solía actuar de forma similar; en muchas ocasiones me llegaban a confundir con un periodista (algo, por otra parte, muy común entre los científicos sociales). Con el trascurso de los meses se modificó sustancialmente mi rol, especialmente en los actos de protesta. Sin embargo, en las reuniones apenas varió significativamente. ¿Por qué en el ámbito de la acción colectiva decidí implicarme desde la militancia y no ocurrió lo mismo en los espacios asamblearios? A pesar de que existiera la misma voluntad de participación en ambos lugares, la contingencia de los hechos acontecidos fue sustancialmente dispar. Tras un análisis a posteriori puedo concluir que los «saberes militantes» sobre los que se debatía y conversaba en el seno de las asambleas eran, mayoritariamente, conocimientos técnicos que no aparecían en ningún manual de movimientos sociales. La incomprensión generalizada de los temas tratados en las reuniones era la tónica habitual durante los primeros meses de observación; utilizaban frecuentemente palabras como «tocho», «condonación», «aplazamiento», «ejecución», «lanzamiento», y todo entremezclado con un lenguaje propio del ordenamiento jurídico. Tras el 
segundo año de investigación empecé a familiarizarme con la terminología, aunque debo reconocer que nunca llegué a adquirir el mismo nivel de comprensión que los activistas de base.

Siguiendo con la autoevaluación de lo que significó el trabajo de campo, me detendré por un instante en otro episodio anecdótico que sirvió para confirmar la complejidad de los procesos de solapamiento de investigación-participación-militancia. Tras un periodo prolongado de estancia de campo y habiendo creado un sistema de relaciones interpersonales y afectivas que trascendía los objetivos de la investigación, me invitaron a participar en una reunión institucional con la concejala responsable del área de vivienda de la corporación local. Si bien se presentaba como una oportunidad para añadir un ingrediente más al estudio, el desarrollo de lo acontecido supuso una nueva píldora de reflexión epistemológica con la que no contaba. La reunión transcurrió con normalidad, es decir, tanto el técnico como la concejal del área de vivienda monopolizaron el encuentro, tan sólo alguna activista realizó alguna intervención puntual. Al finalizar, nuevamente, constaté las deficiencias cognitivas que tenía en los asuntos jurídicos, reconociendo internamente que nada o casi nada de lo que se había hablado lo pude retener. Antes de marcharnos decidimos sentarnos en una cafetería a petición de una de las activistas, ya que acababa de contactar con un medio de comunicación local para que les informara de lo sucedido. Insistió en que debían consensuar las conclusiones y percepciones de la reunión: «¿qué os ha parecido?», «itienen buena voluntad, pero al final no harán nada!», «aunque estas reuniones estén bien, nunca debemos abandonar la calle, que es a lo único que le tienen miedo los políticos», etc. Durante este intercambio de opiniones una de las activistas recibió la llamada que estaba esperando para ser entrevistada, aunque no sería ella la que asumiera tal empresa, ya que se veía incapacitada por problemas de afonía. Propuso a dos compañeros que asumieran tal labor, aunque ambos se negaron. Finalmente me pasaron a mí el testigo; sería yo la persona encargada de hacer de portavoz de la PAH. Lo que sigue a continuación lo extraemos a modo literal de mis anotaciones en el diario de campo:

En ese instante me quedo bloqueado, (...) tenía la responsabilidad de ser representante de la PAH, hecho que me imponía muchísimo (...). Utilicé un lenguaje activista (...). Me estaba dando cuenta de que no estaba explicando nada relacionado con la reunión, por tanto, mientras hablaba intenté recordar a qué conclusiones se había llegado. Siendo sincero, tenía bastantes lagunas sobre las cuestiones técnicas y me vino a la cabeza una posible medida propuesta por el Ayuntamiento acerca de la compra de viviendas para realojar a familias que no tuvieran una alternativa habitacional. Expuse este hecho, aunque no coincidía con la postura que defendía la $\mathrm{PAH}$, por tanto me di cuenta de que había metido 
la pata, por ello le indiqué a la periodista que esperase, y, con los nervios del momento, le pasé el teléfono de nuevo a Desiré [activista que recibió la llamada]. A partir de ahí fue ella la que continuó. Todo se quedó en una anécdota que, sin lugar a duda, voy a recordar siempre (...). Finaliza la entrevista y bromeo con Desiré sobre la «jugarreta» que me ha hecho. Hay bastante confianza entre los dos, ambos nos reímos de lo sucedido (Anotaciones del Diario de Campo: Alicante, 21/01/2016).

No cabe duda de que mi ignorancia se hizo patente. Este hecho acrecentó las dudas sobre si estábamos en disposición de realizar una IM o si, por el contrario, era conveniente recurrir a otros principios epistemológicos más flexibles. La voluntad de seguir acompañando al movimiento social en el empoderamiento de subjetividades subalternas hizo que nos decantáramos, en ese momento, por continuar con la primera opción.

\section{Aportaciones ¿necesarias?}

Una de las funciones que propone Marta Malo (2004) a la hora de realizar investigación militante es adaptar nuestras capacidades a las dinámicas de trabajo y a la producción de beneficio de las organizaciones adheridas. Cuando quien investiga incorpora estas funciones como principio ontológico, la experiencia del trabajo de campo deja de interpretarse exclusivamente desde una dimensión metodológica; no solo tomas conciencia desde el plano teórico e ideológico, sino que asumes un nuevo rol activo y propositivo.

Llegados a este punto, analizaré algunas de las aportaciones que perseguían apuntalar las funciones sobre las que se ha hecho alusión en el párrafo anterior. Siguiendo con el carácter crítico que nos acompaña a lo largo del artículo, haré una distinción entre aquellas aportaciones que no hayan dado respuesta a necesidades de la organización y otras que, en cambio, han servido para reforzar las dinámicas del movimiento social.

Influenciado por mis subjetividades del momento, decidí decantarme por el movimiento antidesahucios debido a su(s) capacidad(es) de agencia para la transformación y el empoderamiento de las clases o grupos subalternos. Esta idea, romántica para algunos, no ha dejado de sobrevolar la mente del investigador y, en consecuencia, he ido creando diferentes materiales para corroborar y difundir este pensamiento. Por ejemplo, tras entrevistar a los activistas me empeñé en diseñar y maquetar los relatos de vida que me habían ofrecido. Lo hice como gesto de devolución y, al mismo tiempo, a modo de espejo en el que pudieran contemplar el hito histórico que estaban protagonizando. En 
términos similares me propuse ofrecerles un vídeo-fotográfico ${ }^{8}$ autoeditado sobre la paralización de un desahucio, ya que, influenciado por una fuerte carga emocional que me acompañaba ese día, estimé oportuno narrar la experiencia vivida a través de un humilde gesto «artístico». Fue publicado a través de redes sociales, aunque tuvo un alcance limitado. A fecha de hoy me pregunto si lo hice como método de autoterapia o si realmente iba en consonancia con los principios de la IM.

Por esas fechas (2016-2017) el movimiento antidesahucios llenaba una gran parte de artículos de prensa, reportajes o noticias en el Estado español. Además, a través del cine se proyectaron películas y documentales ${ }^{9}$ que plasmaban sucintamente las dramáticas experiencias de las familias desahuciadas. En definitiva, identifiqué que se estaba constituyendo un corpus cultural en paralelo a las luchas por la defensa del derecho a la vivienda y, en consecuencia, se hacía plausible la idea de que el emergente escenario sociocultural serviría para reforzar a las organizaciones locales de base. Desde la perspectiva académica se trataba de recursos (in)formativos ampliamente valiosos, pero ¿los activistas lo interpretaban en los mismos términos? Entendía que sí. Resaltaban continuamente la importancia de la formación permanente, por lo que me comprometí a compartir todos los artículos, noticias o reportajes relacionados con la temática. Al tiempo pude comprobar que las noticias o reportajes que llegaron a tener verdadera incidencia serían sólo las que estuvieran íntimamente ligadas a las acciones o actividades organizadas por ellos mismos. Por otra parte, las recomendaciones fílmicas se quedaron en meras anécdotas y, pese a que les sugerí la posibilidad de organizar cines-fórum, nunca se contempló como una actividad viable. Esta situación me obligaba a dejar de mirar hacia el movimiento social en su conjunto, sobre todo a las organizaciones ubicadas en las grandes metrópolis, ya que respondían a lógicas funcionales dispares. Si el anhelo era contribuir, en la medida de lo posible, para ayudar a fortalecer al colectivo, las aportaciones que describo a continuación seguramente tuvieron mayor impacto.

A veces en los cuentos nos dicen que en toda historia siempre hay luces y sombras y que ambas han de contarse para que los acontecimientos adquieran realismo. Hasta el momento todo lo expuesto sugiere oscuridad, sin embargo, el exceso de critica nos puede llevar a estados de escepticismo poco constructivos. En este sentido, tengo el deber de subrayar las fortalezas y así equilibrar la balanza hacia un estado más realista de lo que significó la estancia junto y con el movimiento social.

${ }^{8}$ Invitamos al lector a visionar dicho vídeo-fotográfico a través del siguiente enlace: https://www. youtube.com $/$ watch? $\mathrm{v}=8$ gmS-vnypx 8

${ }^{9}$ Véase, por ejemplo, la película de Techo y comida dirigida por Juan Miguel del Castillo o el documental Sí se puede. Siete días en PAH Barcelona. 
Me referiré, en primer lugar, a mi papel como sociólogo estadista. Si por algo sobresale el sociólogo en el imaginario colectivo es por su capacidad para analizar y trabajar información estadística, y este fue uno de los retos que se me planteó desde el inicio. El colectivo trabaja con una densa base de datos, por lo que me requirieron que realizase algunos análisis para, así, facilitar el trabajo diario, ya sea redactando breves informes o mediante la actualización de la misma. Otra aportación significativa fue la entrega de un estudio pormenorizado sobre la evolución de los desahucios que se habían producido en los últimos años en la ciudad, información que la llegué a analizar desagregada por barrios. La idea atendía a intereses expresos de la investigación, pero finalmente se convirtió en un documento funcional e interno de la organización; incluso los medios de comunicación locales se hicieron eco de los resultados. Por otra parte, mi presencia en las asambleas no era del todo testimonial; asumía, en no pocas ocasiones, el rol de tomador de actas. Fue una práctica común que se explicaba fundamentalmente porque no me separaba del cuaderno de campo y, por tanto, la «mejor» forma de hacer uso de las anotaciones era redactando las actas correspondientes. Sobre el tema de mis intervenciones es preciso puntualizar que la mayoría las hacía a demanda del colectivo, atendiendo a temas tan recurrentes como persuadir a los afectados por desahucio para que se implicaran más en la lucha social del movimiento.

El transcurrir del tiempo y el cúmulo de experiencias compartidas provocaron que la relación investigador-informante se diluyera, estableciéndose vínculos personales que me permitieron ofrecer apoyos emocionales ineludibles. Todos los colegas que han vivido de cerca el desarrollo del movimiento social convendrán conmigo en que las oscilaciones de los estados de ánimo son permanentes y que, por tanto, la función psicológica es fundamental. Los activistas lo saben y actúan en consecuencia, los niveles de compañerismo alcanzan cuotas muy altas. Mi labor no podía ser otra que la de adaptarme a dicha dimensión relacional y practicar IM desde la alegría, la excitación, las risas, pero también desde el llanto, la compasión y el miedo.

\section{REFLEXIONES FINALES}

Llegados a este punto no cabe duda que quien desee adoptar una posición implicada con la acción colectiva deberá tener claro el para qué y el para quién se hace investigación. Aunque, tal y como se ha podido constatar, este hecho no exime de que no nos debamos enfrentar a múltiples sesgos instituidos en la esfera académica. Especialmente en la fase iniciática, es decir, en la propia elección del tema a indagar y durante la fase de diseño metodológico. Es común partir de una hipótesis específica diseñada desde la 
perspectiva del «sujeto conocedor»y, por tanto, es susceptible que esté condicionada por flujos de información científica y hegemónica. A priori, éste sería el escenario de partida ideal para cualquier trabajo empírico, sin embargo, cuando tratamos de canalizar saberes subalternizados para incidir en la transformación social, la influencia tendría que problematizarse. Es común que los estudiosos de los movimientos sociales estemos desarrollando una especie de miopía militante-académica al iniciar un proceso de investigación de estas características. En mi caso partía de relatos sin deconstruir, procedentes de ensayos, investigaciones y testimonios acerca de la historiografía de los movimientos sociales en general, y el arquetipo del activista-militante en particular. Si bien, por un lado, sirvió para involucrarme en un proyecto de estas características, he de reconocer que hubiera sido preferible plantear un debate más amplio que apelara a la deconstrucción de los conocimientos académicos de partida.

Además de los saberes científicos, otra fuerza que mueve a la comunidad académica a autoproclamarse como agente indispensable en la producción de conocimiento especializado es el «ego intelectual». No cuestiono que en pequeñas dosis podría ser, incluso, beneficioso para la consolidación de un proyecto científico de gran envergadura; no obstante, cuando se alude al proceso de investigación militante, el efecto podría resultar contraproducente. Aunque la figura del investigador nos acompaña durante todo el trabajo de campo, el rol varía en función de las relaciones interpersonales que se vayan generando. Es en este segundo punto donde los «egos», esos mismos que nos cortejan al margen de nuestra propia voluntad, podrían llegar a producir estados de frustración y desengaño con nosotros mismos. Pero, ¿es posible deshacernos de este tipo de actitudes cuando la mayoría de veces están latentes? En un ejercicio de responsabilidad sería suficiente con apelar a la honestidad y asumir desde la fase inicial que será un elemento a contemplar en todo el proceso de investigación; se trata, en definitiva, de un aprendizaje permanente en el que cada experiencia servirá para redefinir nuestra práctica investigativa. Por tanto, hacer etnografía aplicada a los movimientos sociales no es sinónimo de realizar IM — si bien es una metodología que facilita esta empresa-, por lo que resulta oportuno revisar críticamente cuál ha sido nuestra labor en el proceso y, sobre todo, reconocer públicamente las limitaciones a las que nos hemos enfrentado. Apelamos a que se incluya como tarea fundamental en el diseño metodológico de cualquier estudio empírico, pero sobre todo en las investigaciones aplicadas pensadas desde marcos militantes.

También es aconsejable acogernos a la máxima que propone Marta Malo (2004) cuando dice: «Si decidimos hacer investigación militante sabemos de dónde partimos, pero no hacia dónde vamos». El ritmo de lo que acontece en estos espacios es tan acelerado que cualquier guion de partida se desmontará rápidamente. Aunque la incerti- 
dumbre es ya un valor asociado a los métodos científicos, también tendremos que ir incorporando progresivamente un nuevo componente: la creatividad. La investigación militante contribuiría, por tanto, al proceso de adaptación de la comunidad académica a la sociedad posmoderna. No obstante, el hecho de que sean los informantes los que determinen la agenda suscita el siguiente interrogante: ¿es posible desde el plano académico sostener una IM si consideramos los plazos, códigos y condiciones prestablecidas? A sabiendas de que es un debate al que se recurre con asiduidad, no debemos perecer en la compleja tarea de aportar ingredientes epistemológicos para reforzar la posibilidad de que la academia sea un agente aliado de determinados contextos de emancipación colectiva.

\section{BIBLIOGRAFÍA}

Agulles, J. (2010). Sociología. Estatismo y dominación social. Madrid: Brulot.

Caballero, J.; Martín, P. y Villasante, T. R. (2019). «Debatiendo las metodologías participativas. Un proceso en ocho saltos». Empiria. Revista de Metodologías de Ciencias Sociales, 44, 21-45.

Castells, M. (2014). Redes de indignación y esperanza. Madrid: Alianza.

Colau, A. y Alemany, À. (2013a). Vidas hipotecadas. De la burbuja inmobiliaria al derecho a la vivienda. Lectio Ediciones: Barcelona.

- (2013b). Si se puede! Destino: Barcelona.

Colectivo Ioé (2004). «Investigación Acción Participativa: propuesta para un ejercicio activo de la ciudadanía». Ponencia presentada en las Jornadas sobre Movimientos Sociales e Investigación Activista. Barcelona. 22-25 de enero de 2004.

Cuesta, R. A. (2010). «El economocentrismo como fundamento ideológico de las ciencias sociales». En ICADE. Revista cuatrimestral de las Facultades de Derecho y Ciencias Económicas y Empresariales, 80. Págs. 111-137. Recuperado a partir de https://revistas.comillas.edu/index.php/revistaicade/article/view/185

Della Porta, D. y Diani, M. (2015). Los movimientos sociales. Madrid: Centro de Investigaciones Sociológicas.

Edelman, M. (1999). Peasants against globalization: Rural social movements in Costa Rica. Stanford, CA: Stanford University Press.

Escobar, A. (1992). «Culture, practice and politics: anthropology and the study of social movements». En Critique of Anthropology, 12(4): 395-432. https://doi.or$\mathrm{g} / 10.1177 / 0308275 \mathrm{X} 9201200402$ 
- (1999). El final del salvaje. Bogotá: Instituto Colombiano de Antropología e Historia y Centro de Estudios de la Realidad Colombiana.

- (2005). Más allá del Tercer Mundo. Globalización y Diferencia. Bogotá: Instituto Colombiano de Antropología e Historia.

Freire, P. (2012 [1970]). Pedagogía del oprimido. Madrid: Siglo XXI.

Graeber, D. (2002). «The New Anarchists». En New Left Review, (13), January-February, http://eprints.lse.ac.uk/id/eprint/53371

- (2009). Direct Action. An Ethnography. Scotland: AK Press.

Gramsci, A. (1973). Consejos de fábrica y estado de la clase obrera. México DF: Ediciones Roca.

- (2000 [1934]). Cuadernos de la Cárcel. Mexico: Ediciones Era. Tomo 6.

Guha, R. (2002 [1982]). Las voces de la historia y otros estudios subalternos. Barcelona: Crítica.

Guiamet, J. y Saccone, M. (2015). «La cocina de la investigación: algunas consideraciones teórico-metodológicas sobre el enfoque socio-antropológico». INTERSTICIOS, 9(1): 81-92, https://www.intersticios.es/article/view/13993

Haraway, D. (1995). «Conocimientos situados: la cuestión científica en el feminismo y el privilegio de la perspectiva parcial». En Ciencia, ciborgs y mujeres. La reinvención de la naturaleza, Madrid: Cátedra, pp. 313-346.

Hoetmer, R. (2009). Repensar la política desde América Latina. Cultura, Estado y Movimientos Sociales. Perú: Fondo Editorial de la Facultad de Ciencias Sociales de la Universidad Nacional Mayor de San Marcos.

Ibáñez, J. (1985). Del algoritmo al sujeto: perspectiva de la investigación social. Madrid: Siglo XXI.

Jabardo, M. (2014). Ser africano en el Maresme. Migración, trabajo y etnicidad en la formación de un enclave étnico. Madrid: Última Línea.

Juris, J. (2007). «Practicing Militant Ethnography with the Movement for Global Resistance in Barcelona». En Stevphen Shukaitis y David Graeber (eds.), Constituent Imagination: Militant Investigations, Collective Theorization. Oakland: AK Press, pp. 164-176.

Kosik, K. (1967). Dialéctica de lo concreto. México: Editorial Grijalbo.

Laraña, E. y Díez, R. (2012). «Las raíces del movimiento 15-M. Orden social e indignación moral». En Revista española del Tercer Sector, 20, pp. 105-144.

Lazar, S. (2008). «Eso es luchar sindicalmente. Ciudadanía, el estado y los sindicatos en El Alto, Bolivia». En Cuadernos de Antropología Social, 27, pp. 63-90. https://doi. org/10.34096/cas.i27.4330 
Lichterman, P. (2006). The Search for Political Community: American Activists Reinventing Commitment. Nueva York: Cambridge University Press.

Macías, C. (2013). «Del empoderamiento a la autotutela de derechos. El caso de la PAH». En El Viejo Topo, 306 (7): 44-48.

Maffesoli, M. (2004 [1990]). El tiempo de las tribus. El declive del individualismo en las sociedades de masas. Mexico: Siglo XXI.

Malo, M. (ed.) (2004). Nociones comunes. Experiencias y ensayos entre investigación y militancia. Madrid: Traficantes de sueños.

Marcus, G. y Fischer, M. (1986). Anthropology as Culture Critique: An Experimental Moment in the Human Science. Chicago: University of Chicago Press.

Melucci, A. (1994). «¿Qué hay de nuevo en los nuevos movimientos sociales?». En E. Laraña y J. Gusfield (eds.), Los Nuevos Movimientos Sociales. De la ideología a la identidad. Madrid: Centro de Investigaciones Sociológicas, pp. 119-150.

- (1996). Challenging Codes: Collective Action in the information Age. Cambridge, Nueva York: Cambridge University Press.

Mignolo, Walter (2003). Historias locales, diseños globales: colonialidad, conocimientos subalternos y pensamiento fronterizo. Madrid: Akal.

Modonesi, M. (2010). Subalternidad, antagonismo, autonomía. Marxismo y subjetivación política. Buenos Aires: CLACSO.

Monjas, M. (2015). Tejiendo la vida frente a los desahucios. Madrid: Huerga y Fierro Editores.

Nash, M. (2004). Mujeres en el mundo. Historia, retos y movimientos. Barcelona: Alianza.

Ortega, J. (2015). «El papel de los nuevos movimientos sociales en contextos de marginalidad: el caso de la PAH Alicante». En E. Nos, A. I. Arévalo y A. Farné (eds.), \#comunicambio: Comunicación y Sociedad Civil para el Cambio Social. Madrid: Fragua, pp. 223-235.

Rockwell, E. (2009). La experiencia etnográfica: historia y cultura en los procesos educativos. Buenos Aires: Paidós.

Santos, B. de Sousa (2006). «La sociología de las ausencias y la sociología de las emergencias: para una ecología de saberes». En Renovar la teoría crítica y reinventar la emancipación social (encuentros en Buenos Aires). Buenos Aires: Clacso, pp. 1341.

- (2013). Descolonizar el saber, reinventar el poder. Santiago: LOM Ediciones.

Sipivak, G. G. (2003[1985]). «¿Puede hablar el subalterno?» En Revista Colombiana de Antropología, (39): 297-364. http://www.scielo.org.co/scielo.php?script=sci_arttext\&pid=S0486-65252003000100010\&lng=en\&nrm=iso 
Taberner, J. (2014). Movimientos sociales en la era global del precariado. Madrid: Fundación Emmanuel Mounier.

Tilly, C. (1978). From Mobilization to Revolution. Nueva York: Random.

- (2009). Los movimientos sociales, 1768-2008. Desde sus orígenes a Facebook. Barcelona: Crítica.

Torres, A. (2008). «Investigar en los márgenes de las ciencias sociales». En Folios, (27) Págs. 51-62. https://doi.org/10.17227/01234870.27folios51.62

Varela, A. (2013). Por el derecho a permanecer y a pertenecer. Una sociología de la lucha de migrantes. Madrid: Traficante de Sueños.

Zemelman, H. (1987). Uso crítico de la teoría. México: El Colegio de México.

- (2005). Voluntad de conocer. El sujeto y su pensamiento en el paradigma crítico. Barcelona: Anthropos.

Zemelma, H. y León, E. (1997). Subjetividad: umbrales del pensamiento social. Barcelona: Anthropos.

Ziebechi, R. (2007). Autonomías y emancipaciones. América Latina en movimiento. Lima: Universidad Nacional Mayor de San Marcos. 